\title{
The Theory of Leadership and the Way of Its Application in Greek Business Actuality
}

\author{
Ioanna Dimitrakaki \\ Department of Management, Faculty of Management and Marketing, Neofit Rilski University, Blagoevgrad, Bulgaria \\ Email address: \\ iondimi@hotmail.com \\ To cite this article: \\ Ioanna Dimitrakaki. The Theory of Leadership and the Way of Its Application in Greek Business Actuality. American Journal of \\ Management Science and Engineering. Vol. 4, No. 2, 2019, pp. 17-25. doi: 10.11648/j.ajmse.20190402.11
}

Received: March 26, 2019; Accepted: May 21, 2019; Published: June 10, 2019

\begin{abstract}
In the complicated and difficult era in which we live, when the future is uncertain mainly in the labor market, when economy suffers one of the worst crises of the last decades due to the universal financial crisis, a continuous adjustment regarding both the business sector and the leading executives of businesses is required, because the leader abilities are the motivating force for the individual development and the realization of the vision of businesses. The target of this article is to highlight the way in which the theory of leadership in Greek actuality is applied, the styles that are adopted and the degree of its influenceon the efficiency of the employees. For this reason, two industrial businesses, which operate in the area of Macedonia, as the object of the research were chosen. Firstly, a theoretical approach of the subject via secondary research of sources (theory of Target and Path) took place and then secondary research (quantitative and qualitative) so that the importance of practice through the theoretical application of the model in the two businesses is noted. From the drawing of conclusions, it seems that the cooperation of leader executives with teams and subordinates which predominatesin both businesses is excellent. This fact shows the excellent organization and collectivity that predominates and the fact that the leaders use the model of Path-Goal. However, proposals regarding the leader style, mainly that of a business that pertains to anxiety and fighting against it aims at the increase of the efficiency and development of the three businesses.
\end{abstract}

Keywords: Leadership, Leader, Offices, Leader Behavior, Leader Style

\section{Introduction}

In a complicated era, when everything changes, when the future is uncertain and hardly can be foreseen, when insecurity dominates in the business sector, the companies that develop within the limits of this difficult competitive environment, can difficultly and attentively find the way of success. The suitable mechanism of motivation to success is Leadership.

The modern topic of leadership has been researched in the international bibliography thanks to a lot of different definitions. In every case, all the researchers agree that there is a difference between managers and leaders Their basic difference is that the former get involved in solving administrative problems, whereas the latter search the possibilities to exceed them, in order to fulfill a business vision [1].

In every case., it has been clear that the need for leaders in societies is important, as long as people will differ in the way that understand and handle the dynamic complication of life, deal with the phenomena that result every day, control emotions, desires, passions and ideas, accept the responsibility for their thoughts, sayings and actions, seek spiritual aspects and roots for the decisions, and communicate, discuss, negotiate and seek common solutions to combine logic with intuition, emotions, will, effort, action, and play roles in readiness.

Leadership is a relation between the leader and the follower, the situation that exists and the target to be achieved. The data that differentiate the various types of leadership are related to the way in which this relation is defined and operated. Its operation develops inside the environment, which is significantly influenced by its rolemodels, values, strategies, targets, and philosophies and by the people with whom it cooperates. What businesses need in a world which changes rapidly is a capable leader that will create and impart visions and strategies.

The role of a leader is being able to motivate and inspire the substituents. Moreover, the importance of the problem is 
double. In a theoretical level, an in-depth study in regard to the types, styles, and theories of leadership was conducted.

In a practical level, today's situation of leadership was studied via primary research, tracking the points for intervention and improvement. To achieve this purpose, research was conducted in two businesses ofdifferent activities, which are of Greek interests, in particular, in EURIMAC S.A., a pasta industry headquartered in Kilkis and ZANAE S.A., an industry of food standardization headquartered in Thessaloniki.

\subsection{Purpose of Research}

The purpose of research in this article is to describe the situation in Greek entrepreneurship with regard to the principles and types of leadership. More specifically, the determination of results of leader behavior of executives in two different -regarding the object-businesses was measured with respect to the motivation and efficiency of employeessubordinates.

\subsection{Targets of Research}

The targets of this research are the following:

1. The literature review of theories and models of leadership and the parameters that determine the nature of leadership in our time.

2. The choice of the suitable model of leadership as a benchmark for the needs of the article.

3. The presentation of the implementation of leadership in Modern Greek entrepreneurship, with regard to the forms, types, and styles of leadership that apply.

4. The relation of leadership and motivation between leaders and subordinates but also the ways in which their interest and desire to contribute to the implementation of the corporate vision and corporate strategy increase.

5. The detection of deviation between theory and action with respect to the implementation of leadership in Greek actuality and proposals for its more effective application.

\subsection{Reasons for the Choice of This Topic}

The reasons forthechoice of this topic are the following:

1. The challenges of the research to people that are occupied with the business management and departments.

2. The enrichment of knowledge of researchers and their experience about theory and action which is related to leadership.

In that case, it is particularly important for the investigator to focus on the way in which leadership can be applied in the workplace, especially nowadays, when the rapid social, financial, and cultural changes directly determine the office environment.

Another reason for which this topic was selected is that the researcher attempts to answer the main pertinent issues, such as what leadership is, what a leader is, which the reason for their existence is, what the effective leading behavior consists of, as well as which personality characteristics values, knowledge, and abilities the effective leadership demands for the commonweal, both in the short and in the long term. Last but not least, the researcher is able to make some necessary recommendations for the development of leading abilities by the enrichment of their knowledge.

\subsection{Structure of the Article}

The structure of the article includes the introduction, the theory, with the main theoretical approaches of leadership, meanings of leader, types of leadership, leader styles, models of leadership and analysis of the theoretical model of choice, the presentation of methodology research and steps that were followed for its conduct and, after the analysis of the data of research, the conclusions which result from the analysis of the data, as well as the proposals and benefits, are described.

\section{Literature Review}

\subsection{Meanings of Leadership and Leader}

Although a lot of definitions with respect to the definition of leadership exist, one of the most distinguished definitions is that of Bennis W. according to whom "Leadership is the most conspicuous daily phenomenon in the earth that we have little understood" [2].

Leaders are those that have a clear and predefined sense of purpose and vision. According to Chinese philosophy, the leader should be characterized by five virtues, which are humanism, morality, decency, wisdom, and reliability. Consequently, the meaning of leadership has a direct connection with the change, progress, and the best future for the people.

Leadership means to direct the perspective and visions of people at a higher level, to improve the performance and efficacy of cooperatives in high levels, and to build personalities that are free from common weaknesses and mild performances. According to the dictionary of Modern Greek language of Pataki editions, the definition of leadership is leading, guidance and those who exert it) [3].

Peter Drucker wrote regarding the question: What abilities does leadership require? Leadership requires basic abilities. Nothing is more difficult to be determined nothing is more difficult to change than the basic abilities. Especially, the original leader is not necessarily charismatic; he is careful and he tries to give motives that provide ethical values, recognition, and reward [4].

According to Yukl, leadership is a procedure of influence and is defined as: "The procedure of influence, which implies the determination of objective targets of a team or organization, the creation of motives for the realization of the project and its contribution to maintaining the team and the culture" [5].

\subsection{Types of Leadership}

The character of a leader is a very important parameter for the efficient leadership, yet it is not enough, given that the abilities and knowledge to realize the efficient 
implementation, fulfill the values and visions, maintain the principles and philosophy so that the leader promotes the desirable result are essential [6].

Within this framework, a leader can be efficient, playing four basic roles that are the following:
A. The visualizer
B. The strategic
C. The facilitator
D. The contributor

\subsection{Leader Styles}

No leader style is efficient and compatible with every situation and every manager. The basic question that arises is which form of style is suitable in every specific time an din which way and conditions it is so. The kind of style that will be adopted depends on a lot of factors such as personality, education, experience, and values system of a manager, character, education, knowledge of the project and expectations of executives, technology of the organization, structure, policies, leadership style of superiors [7].

Moreover, other categories of leader styles are the following [8]:

Visualizer: his characteristic is related to the fact that he inspires his subordinates.

Friendly: his characteristic is being friendly with everyone.

Adviser: his characteristic is that he listens to his subordinates.

Democratic: one of the most basic purposes of the democratic leadership style in management is the creation of such conditions that increase the creativity, productivity, and morale of employees.

Peacemaker: his basic elements are the strong will for achievements and the high personal standards that he has.

Autocratic: his characteristics are making the decisions by himself and delegating them to the team for implementation.

Authorizing: his characteristic is the fact that he has a limited role. The team makes the decisions, without being influenced by the leader.

Transformer: a leader who stimulates colleagues and subordinates about the project.

Reddin claims that different situations require different styles and their efficacy depends only on the conditions in which the leadership is applied. He accepts that the forms of leadership of relations, finishing, sharing, and loyalty are the four basic styles, each one with its efficient or inefficient corresponding, according to the situation in which it is used [9].

\subsection{Models of Leadership}

The meanings of management and leadership are complementary and interacting. Management mainly encounters complexity in modern organizations while leadership encounters the changes of the modern world [10]. One person can exert management and leadership, provided they have suitable characteristics.

There are a lot of models of leadership, yet, for the needs of this article, five theories of leadership, those of Likert,
Blake-Mouton, AIDAR Model, Blanchard \& Hershey and KOUZES are mentioned. A manager in a company should have elements from all five theories that are mentioned above in order to be a leader.

More specifically, according to the theory of Likert, he should develop the participatory style, in order to create a climate of reciprocal cooperation with his subordinates, communication, and participation in making decisions, so that the targets are actualized through common decisions and procedures.

Likert developed the theory on the basis of four systems (styles) of leadership:

1. Autocratic

2. Benevolent

3. Advisory

4. Participatory

According to Likert the most efficient style of leadership is the participatory one.

According to Blake-Mouton, he should be interested both in the results of his projects and his team in order to be an effective leader. It is a complicated combination, in practice, according to which he scores well if he manages to be interested in the same degree in production and human factor. This is named: styles of management.

According to the AIDAR model, a manager should have the three basic attributes that characterize him as al eader, i.e. the development of the abilities of the people that constitute the team, the creation of togetherness and focusing on specific company sales targets, such as the increase of the market share and the finding of new clients.

According to the occasional model of Blanchard \& Hershey, a manager should adopt the participatory style according to which he will urge his subordinates to take initiatives, offering them the suitable support and guidance in order to acquire a leader personality.

Finally, according to KOUZES, the basic elements that a manager who is a leader should have is to create the conditions of development of the creativity of his subordinates, the conception of a vision and its connection with their daily life, the creation of a cooperative climate, the continuous improvement of individuals, through their mistakes, the reward for their good job, and the suitable programming of activities.

\subsection{A Theoretical Model of Choice. The Theory of Target and Path}

The leadership theory of target and path accepts that the performance of subordinates is influenced by the degree to which the manager meets their expectations. This theory has roots in the theory of motivating expectation [11].

This theory gives emphasis on how a leader influences the perception of his subordinates regarding the targets of the project, whereas he highlights the relation between those two targets and the ways of their approach i.e. "the paths" towards them.

The theory of House includes four styles of leadership, which are: 
1. The directional style of leadership. This style is basically autocratic.

2. The reinforcing style of leadership. In this style, the manager is interested in the needs of the subordinates and their prosperity.

3. The participatory style of leadership. In this style, the manager asks the opinion of his subordinates about making decisions.

4. The leader style of achievement. In this style, the manager delimits high and challenging targets, while he shows that he believes his subordinates will finally succeed.

Path-Goal theory of leadership provides a framework which explains the degree of success and flexibility aiming at the efficacy of the team, the increase of motivations, the high level of projects, and rewards [12].

Characteristics of the theory of target and path

The characteristics of this theory are the following [13]:

A. The characteristics of subordinates, which help the manager are:

i. the abilities, knowledge, and experience of the subordinates to realize the project

ii. the needs of every subordinate and the degree of control which they believe they have on events and results.

B. The characteristics of the situation and structure of responsibilities.

If the responsibilities are structured, the reinforcing and participatory leader style will be more efficient. Subordinates that work in no structured responsibilities prefer the directional style of leadership. When the responsibilities are not structured, a manager should word the tasks with clarity and determine the subordinates' expectations. According to this model, subordinates are tested in three basic levels which appertain to the need for participation in the team -in that case, the reinforcing style is preferred-, the feeling of taking control, where the participatory style is preferred and the feeling of being able to accomplish a goal, where the directional style is much less preferred.

Reasons for the choice of a theoretical model

The reason that the target and path model was chosen is the fact that it fits, due to its individual elements, with the field of businesses in Greece. It also includes elements that affect leadership, if we take into consideration the theories of motivation, anelement which is essential in the field of Greek businesses. Finally, the reason for which this model is chosen is that the style of leadership of the model fits with the style of management of the businesses where the research was conducted.

\section{Methodology of Research}

\subsection{Determination of the Targets of Research}

The target of the article is to track the existence of types of leadership which exist in Modern Greek businesses, through different types of activity.
More specifically, the basic targets of the research are the determination of the types of leadership that exist in businesses under consideration, the tracking of theories of leadership that are applied in modern business branch and its connection with the motivation of employees.

\subsection{Methods of Collection of Data}

For the needs of the quantitative research, a questionnaire with predefined and standard questions was used, so that the respondents can answer the questions easily. The questionnaire was delivered to 40 subordinates of the two businesses from a total "population" of 350 employees and was the sample of the quantitative research.

ANALYTICALLY, THEY WERE DELIVERED:

I. To 25 subordinates of ZANAE S.A. and

II. To 15 subordinates of EURIMAC S.A.

The questions of the questionnaire were asked from 10 January until 30 January 2019.

For the needs of the article, within the framework of qualitative research, interviews were conducted, in order to collect added supplementary elements and information about the topic of leadership and its application in the businesses under consideration. Here, the structured interview was based on strictly determined general questions which were asked to all the respondents in the same way [14].

The interviews that were conducted for the needs of qualitative research are the following:

i. An interview with the manager of EURIMAC S. A.

ii. An interview with the managers of the departments of sales and production of EURIMAC S. A.

iii.An interview with the managers of the departments of sales, production, supplies and another one with the manager of the tomato puree factory of the company ZANAE S. A.

The interviews were conducted from 20 until 25 January 2019.

The interview contributes to the development of communication with the flexibility and freedom in which it is directed by the researcher, allowing the drawing of elements that are essential for the needs of the article [15].

Pilot test

Before the questionnaire was delivered to the respondents a sample of three people from the main sample that was used in the research was tested. After the evaluation and the correction of some questions, the final form of the questionnaire which was given to the whole sample was determined.

Exporting of results

The results were exported through the classification of the answers into the corresponding categories.

Evaluation of results

Conclusions regarding the procedure of exerting leadership that each one of the businesses follows were drawn by the evaluation and analysis of results.

\section{Result and Discussion}

Further down, the results of the research are commented 
according to the answers that were given and the conclusions and suggestions of improvement of the two companies where the research was conducted will be mentioned so that the targets of this research are efficiently achieved.

\subsection{Findings and Conclusions That Result from the Quantitative Research}

According to the results of the quantitative research in the companies that were tested (which are ZANAE S. A. and EURIMAC S. A.), the percentage of male employees is bigger $63.22 \%$ than that of female ones $36.78 \%$. We can observe that male employees are more.

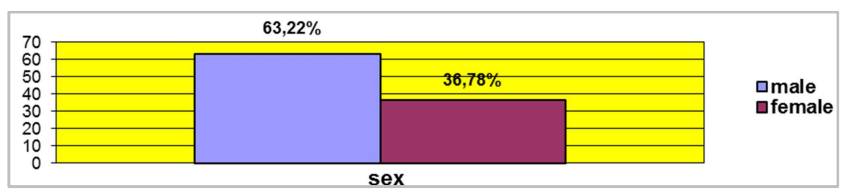

Figure 1. Percentage of male and female employees.

In Figure 2, we can observe that the percentage of those that have a subordinate is $17.24 \%$, while those who do not have a subordinate are $82.76 \%$. The numbers show us that there are not a lot of grades in the hierarchy of employees because most of them do not have a subordinate.

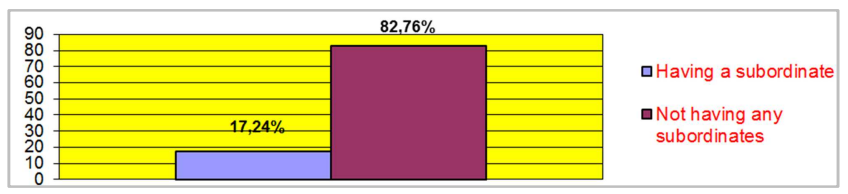

Figure 2. Position in the business.

The $42.53 \%$ are high school graduates and the $57.7 \%$ are university graduates. It is important for someone to observe in Figure 3 that the level is very high although it is related to branches where employees with a high educational level would not be necessary.

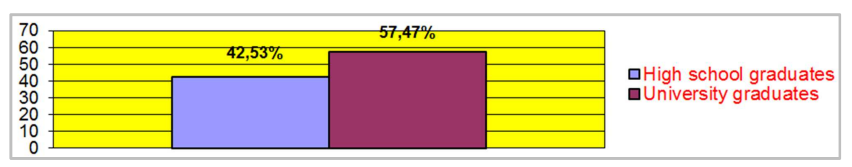

Figure 3. Level of education

In the next question (Figure 4), we conclude that in general, the employees are happy with their superior based on the answers that they gave. The biggest percentage $69.32 \%$ believes that their superior allocates projects to the members of the team correctly, whereas $27.37 \%$ answered: Very often, and $3.31 \%$ answered: Not very often.

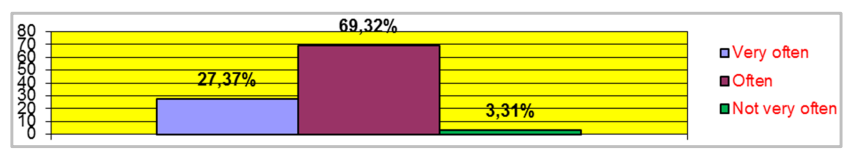

Figure 4. The result of the question: Does the superior allocate projects to the members of the team correctly.
The mentioned conclusion of Figure 5 raises also a question due to the fact that $94.2 \%$ of the sample answer that the superior is very often and often objective regarding the solving of conflict, whereas only $5.8 \%$ of the respondents answered: Not very often.

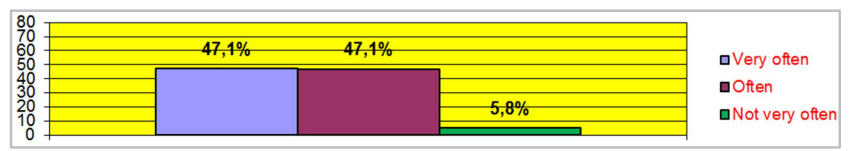

Figure 5. The result of the question: Is the superior objective in the solution of conflicts.

Furthermore, in Figure 6, we can see that the superiors try hard to make the subordinates understand that it is very important to have a common way of thinking with the company. Someone can understand that from the answers in the question if the superior shares his perceptions with the team in order to create a common strategy. The results show that $48.9 \%$ answer: Often, $37.8 \%$ answer: Very often, $5.6 \%$ answer: Not very often, whereas there is a percentage of $7.8 \%$ that do not answer. The last percentage that is very big and has not answered the question raises a question. Maybe the fear that the results will be made known made some people prefer not to answer than express a possibly negative view.

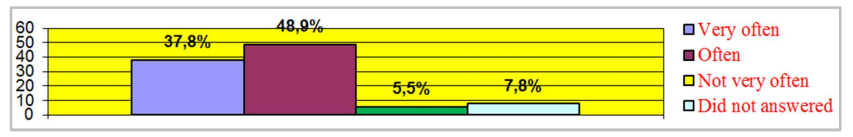

Figure 6. The result of the question: Does the superior share his perceptions with the team in order to create a common strategy.

As we can see in Figure 7, the superiors of the branches seem fair. The answers that were given regarding the question if the superior rewards the job of his subordinates reveal this. $22.89 \%$ answer: Very often, $61.44 \%$ answer: Often, while the rest $15.67 \%$ answer: Not very often. Studies have shown that justice inside companies is a determining factor because it increases the performance of employees. If an employee knows that he will be fairly rewarded for his effort he is willing to do his best.

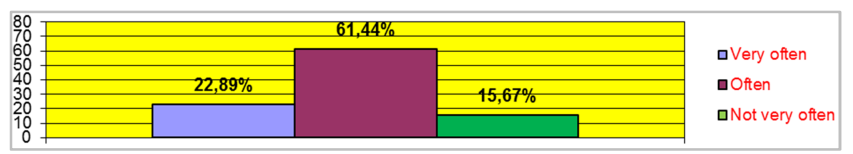

Figure 7. The result of the question: Does the superior reward the job of his subordinates.

Justice is also revealed through the answers to the question if the superior is objective in his judgment regarding the evaluation of the performance of his subordinates. According to the results, the percentages are the following: $44.31 \%$ of the employees answer: Very often and often, while a small percentage of $11.38 \%$ answer: Not very often (Figure 8 ). 


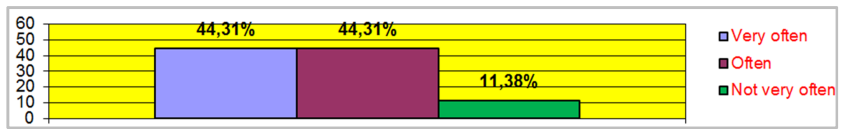

Figure 8. The result of the question: Is the superior objective in his judgment regarding the evaluation of performance of his subordinates.

In Figure 9, we can observe that the answers to the question if the superior promotes the results of the project of his team within the company make obvious that superiors want to reap the benefits of their success by themselves although they may be a result of collaboration with their subordinates. The percentage of the subordinates who answer: Very often in both questions is smaller, whereas the one of those who answer: Often is bigger. Regarding the question if the superior promotes in the internal of the business the results of the project of his team, $35.22 \%$ answer: Very often, while $61.36 \%$ answer: Often, a very small 3.4\% answer: Not very often.

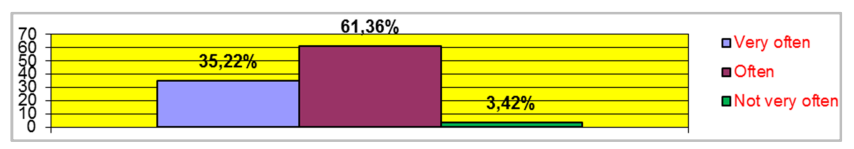

Figure 9. The result of the question: Does the superior promote the results of the project of his team within the company.

Also, regarding the question if the superior incorporates the proposals of their subordinates into the final project, $38.82 \%$ answer: Very often, $57.64 \%$ answer: Often, and finally $3.53 \%$ answer: Not very often (Figure 10 ).

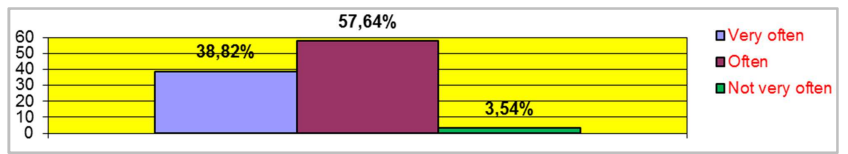

Figure 10. The result of the question: Does the superior incorporate the proposals of his subordinates into the final project.

Regarding the salary, according to Figure 11, there is dissatisfaction because a big percentage of the sample answers: Quite satisfied to the question if the employees are satisfied with the earnings that receive from their company. All the percentages are the following: 5.6\% answer: Absolutely satisfied, 32.2\%: Very satisfied, 46.7\%: Quite satisfied, 12.2\%: Not especially satisfied, 1.1\%: Not at all satisfied, while $2.2 \%$ have not answered at all.

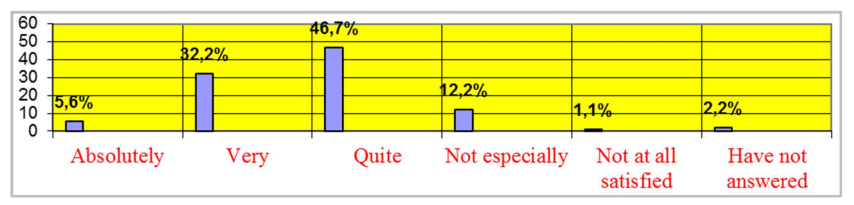

Figure 11. The result of the question: Are you satisfied with your earnings.

In Figure 12, we can see that justice can be made obvious one more time through the question if they work in a company where promotion is an award of a good job.55.6\% answer: I agree, $28.9 \%$ answer: I neither agree, nor disagree, 7.8\% answer: I absolutely agree, $4.4 \%$ answer: I disagree,
$1.1 \%$ answer: I totally disagree and there is a percentage of $2.2 \%$ which has not answered this question.

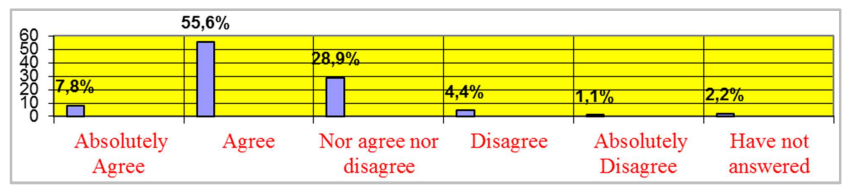

Figure 12. The result of the question: Do you work in a company where good job is rewarded with a promotion.

Someone can understand that there are conflicts during the project by observing Figure 13. Regarding that question, $58.9 \%$ answer: I agree, $12.2 \%$ : I nor agree, nor disagree, 14.4\%: I absolutely agree, $11.1 \%$ : I disagree, $1.1 \%$ : I absolutely disagree, and there is a percentage of $2.3 \%$ which has not answered this question.

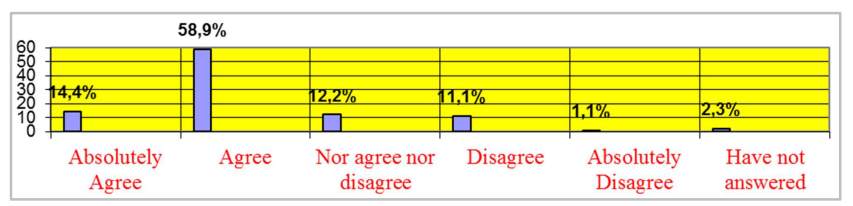

Figure 13. The result of the question: Are there often any conflicts between members of your team during the project.

Regarding the capability of the superiors, as it can be seen in Figure 14, all employees, apart from a percentage of $2.2 \%$ that has not answered, answered that the superior is quite capable in his work. $38.9 \%$ absolutely agree and $58.9 \%$ agree.

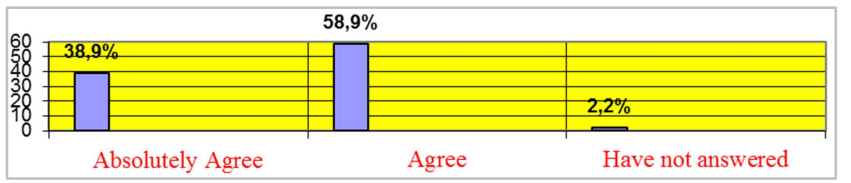

Figure 14. The result of the question: Is your superior fairly capable in his work.

Another ascertainment, when observing Figure 15, is that the company subsidizes the employees on a continuous basis regarding their education. $46.7 \%$ absolutely agree to that, $40 \%$ agree, $10 \%$ neither agree nor disagree, while $3.3 \%$ have not answered the question.

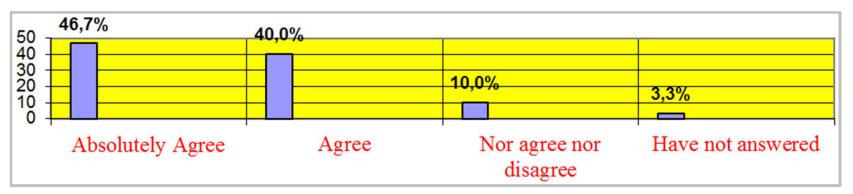

Figure 15. The result of the question: Does the company in which you work subsidize the education of its employees on a continuous basis.

We continue the quantitative research with its results and the conclusions which are drawn. At this point, we should call to mind that this part has been conducted with questionnaires answered by the directors of the departments. The companies of this branch have a typical organization, as $83 \%$ of the sample attests. Procedures are also stable. The 
reward system is analogous to what the employees should be rewarded with. In these companies, the goals are set according the turnover or, more specifically, according to the sales elements. The methods, systems, and ways of instigation which a business uses are related to the moral and financial reward. Of course, the latter is predominant. The departments of production set their goals according to the predictions of the year. It is an important fact that the tested companies have the suitable systems of training their employees, which attests both their development and the quality of their products. The development of the employees of the company takes place by their feeling safe and stable.

\subsection{Conclusions that Result from Qualitative Research}

In this unit, the conclusions of qualitative research which are the following are presented:

1. Regarding the structure of the organization of every company, the businesses that participate in our research have a typical organization which is determined from their organizational structure. Their typical organization is related to the division of labor among members or teams of the businesses. Power and responsibility are devolved to the various levels of the management hierarchy through the typical organization.

2. The next conclusion has to do with the procedures that are followed in every company. The companies ZANAE S.A. and EURIMAC S.A. have developed stable procedures and ways of work, with collection and evaluation of experiences and knowledge of all employees. Thus, the best way of operation develops. Everyone should be trained according to that and apply it. Regarding the target of the departments separately and especially those of production in every business, it has to do with the projects and provisions of every year. The methods and ways of motivation are moral and material rewards in all the tested businesses. As for the educational systems, the managers seem sure about their personnel. They unanimously assume that they have an adequately trained personnel that is capable to produce for the business and hit the targets of the business. We continue with the way of development of employees. For one more time, the managers obviously understand that the education of its personnel is very important for the business. Besides, businesses know what is good for them. They know that the education of their personnel contributes to achieving the goals that have been set since the beginning of the year.

3 . The next conclusion has to do with the ways of making decisions, togetherness in them, and the style of leadership. As it can be seen by the answers of managers, the advisory style of leadership applies in both businesses. In this, the leader trusts the members of his team using bidirectional communication for the knowledge of his subordinates. An Advisory style of leadership means discussing the topics with one's subordinates before deciding what should be done for the achievement of the goals. The above-mentioned style of leadership during making decisions can be seen for one more time through the answers that the managers of the two companies give to the question about togetherness in making decisions.

4. Finally, we should mention the conclusions regarding how the evaluation of satisfaction of employees of a business is conducted. The businesses that are studied in this article use the theoretical model of Target and Path. The leadership theory of Target and Path accepts that the performance of subordinates is influenced by the grade to which the manager satisfies their expectations.

\subsection{Total Conclusions}

Comparing the results of research with the theory of Target and Path, the conclusions that result are that the leadership style of the theory of Target and Path is applied by the two businesses where research was conducted. Specifically:

The leader style: It can be considered participatory and reinforcing, apart from the manager of the factory of EURIMAC S.A. that can be characterized directional.

The grade of subordinates' support: It is usually realized through the reinforcing style and that can be proved by the answers of subordinates that answer that superiors generally care for the needs of subordinates.

Achievement of goals, performance, and motivation: They are mainly accomplished with the participatory style and that can be proved by the fact that almost all leaders of the research set general goals for all departments. As regards the conformation of financial or typical motivations, the participatory style is applied by motivating cooperators to achieve the goals and proposals.

The grade of the superior's participation: It is accomplished mainly by the reinforcing leadership style and that can be proved by the great interest that superiors show in their teams, a fact that increases the satisfaction of subordinates.

Rewards and satisfaction: They are realized through the participatory style and that can be proved by the fact that managers claim that the system of rewards is right and attempts are made to achieve a general agreement as regards the financial satisfaction of employees.

Education, development: They are accomplished by the participatory leadership style and more thoroughly for the methods of education while the management style is used for the implementation of education where parameters of cost enter.

\section{Proposals}

\subsection{Motivation, Performance, Satisfaction}

Regarding the possibility of participation of employees and executives in making decisions, understanding the relationship that is found among need, motivations, and targets, the participatory style is proposed because both employees and executives become more responsible when making decisions and that results in a better performance. The success of a rewards system is connected with the ability of the manager to connect the reward with the performance in a reliable way [11]. The supporting style is 
proposed in the cases of motivation and satisfaction combination when there is a wrong impression that the motivation depends only on the money. As long as the perception that rewards are better than performances prevails (It does not matter if we know well the economic results of the company or not.) the reinforcing leadership style is proposed so that the leader will be able to satisfy both the employees and the company.

In cases that there is a need for further improvement of performance, the supporting style is proposed because it has a very positive influence on the company which results in the development of responsibility and the most efficient performance.

\subsection{Education, Selection, Development}

The social changes, the rapid development of technological innovations and new information make the education of employees in businesses essential. Taking into consideration that the success of education depends on the planning of the educational program, the participatory leadership style is proposed so that the cooperators are able to express their preference or propose a way of education. Employees should admit that education is essential and understand that the result will first benefit them (possible adjustment of salary or promotion) and then the business where they work in order for the education to be considered successful.

As regards the organization and realization of the educational program, the supporting leadership style is proposed so that the manager creates a suitable climate for the success of the program. The selection of cooperators is one of the most basic factors for the successful cooperation between executives and managers. The leader should find, record and evaluate the characteristics of his cooperators and choose those whose culture, education, choice, and development, fit with the structure of the business.

Regarding the selection, the participatory leadership style is proposed so that a suitable climate of cooperation as regards the choice of cooperators is created. The factor of development that interests the employees and the business is one of the priorities of a leading manager. Thus, the supporting leadership style is proposed for the creation of a climate in the relationships among employees, development, and the business which will have satisfactory results for the company.

The evaluation of the performance of employees is proposed to be one of the basic activities of the manager so that the strengths and weaknesses of a person can be found. One of the tools of evaluation is the evaluation form thanks to which the rate of development is found by the manager, a fact that will benefit the manager making him know the development policy and the business.

An evaluation of performance is proposed in the production department of EURIMAC due to the nature of the program of production on the condition that the program of sales is predefined due to presales.

\subsection{Anxiety, Deviation, Participation}

According to Dohrenwend and Dohrenwend, the anxiety shows an internal condition of a person or a reaction that is caused by stimulation [11]. All results and problems that create the anxiety have an important influence on the performance of the employee and on the cost of the business.

The reinforcing leadership style is proposed for the treatment of anxiety. Priority is given to the encouragement of employees by the manager but also the finding of other ways of psychological support. A deviation regarding the budgeting of the company often exists in the production data.

In this case, the participatory leadership style is proposed so that the manager stimulates employees through cooperative procedures to realize that maybe the deviation is due to them. The role of a manager is, apart from others, to get in contact with many people and teams inside the business and very often with executives, so that he is informed about what happens in the business. As regards the total making of decisions, the setting of goals, and the results, the participatory leadership style is indicated so that the results of the business are satisfying.

Over the years, businesses have been at the heart of many discussions, both at a national and at a European level due to their special characteristics. Businesses have to develop effective ways of leadership for their survival and long-term development.

Thus, one can understand that the managers of businesses should not be isolated, sitting unapproachable in their offices, but, in contrast, they ought to be communicative and give enough freedom to their subordinates both regarding doing various things by themselves and openly making suggestions and expressing their views. Furthermore, managers should approach their subordinates politely and a climate of intimacy should exist between them. It is also necessary for a director to be able to change his leading behavior according to the particularity of every situation, which presupposes flexibility, taking into consideration the social, cultural, financial, and technological environment which has been continuously evolving.

\section{Conclusion}

The conviction that dominated until the end of the $19^{\text {th }}$ century that the right superior is the one that manages in an authoritarian way, using the employees as a means of production has disappeared in our days. This image gradually changed.

In our days, the leader conceives a vision for the business. He makes employees believe in this and leads them in its realization. He helps them realize their abilities and make the most of them. The decisions to which he will come are determined by the targets of the business which manages.

From the research of the present article, it seems that the method in which the leader influences the subordinates does not differ from one leader to another, apart from some cases, where the difference is determined by his leadership style, 
which is the product a) of his attitude towards people, b) of the power that he has and c) of the interest that he shows. The qualitative research contributed to the enrichment of knowledge in the topics of leadership and ways of management.

\section{References}

[1] Burandas, D. (2008), Panorama of the theories of leadership. What is a leader and in what differs from a manager, Scientific Marketing, p. 102.

[2] W. Bennis. On becoming a leader. Cambridge, AddisonWesley, 1989, p. 197.

[3] A modern dictionary of the Greek language. Athens: Pataki, 1996.

[4] George, B. (2004). The journey to authenticity. Leader to leader, pp. 29-35.

[5] G. Yulk, Leadership in organizations. NJ: Prentice Hall International, 2002, p. 253.

[6] D. Burandas, Management. Athens: Benou, 2001, p. 101.
[7] Terzidis, K. and K. Tzortzakis, Management human resources. Athens: Rosili, 2004, p. 45.

[8] C. Kanellopoulos, Management. Efficient management in businesses. Theory and Practice. Athens: International Publishing, 1990, p. 67.

[9] J. W. Reddin, The 3D Management style theory training and development journal, 1967, pp. 8-17.

[10] Blesios, N. (2001). The difference between management and leadership. Harvard Business Review 29 (2), p. 25.

[11] M. Zavlanos, Organizational behavior. Athens: Stamouli, 2002, pp. 132, 137, 290.

[12] Dixon, M. L. and H. L. Kozloski (2010). The impact of pathgoal leadership styles on work group effectiveness and turnover intention. 1, 4 .

[13] G. Siomkos, Research market. Athens: Stamouli, 2008, p. 311.

[14] T. Iosifidis, Analysis of quantitative data. Athens: Kritiki, 2003, p. 40.

[15] M. Petrakis, Research marketing. Athens: Stamouli, 2006, p. 97. 